\begin{tabular}{c|c|c}
\hline JURNAL PENELITIAN KESMASY & VOL. 1 NO. 2 & $\begin{array}{c}\text { EDITION: NOVEMBER 2018 - } \\
\text { APRIL 2019 }\end{array}$ \\
\hline \multirow{2}{*}{ RECEIVED: 17 FEBRUARI 2019} & http://ejournal.delihusada.ac.id/index.php/JPKSY & ACCEPTED: 28 APRIL 2019 \\
\cline { 2 - 3 } & REVISED: 18 MARET 2019 & ACE
\end{tabular}

\title{
HUBUNGAN SOSIAL EKONOMI DAN PERILAKU HIDUP BERSIH DAN SEHAT DENGAN KEJADIAN DIARE PADA BALITA DI DESA BARU KECAMATAN PANCUR BATU
}

\author{
SELAMAT GINTING \\ Institut Kesehatan Deli Husada, Jalan Besar Delitua No. 77, Kab. Deli Serdang \\ e-mail :selamatginting18@gmail.com
}

\begin{abstract}
According to the World Health Organization (WHO) diarrhea is liquid bowel movements more than three times in 24 hours, and focuses more on the consistency of feces than the frequency of defecation. Diarrhea is still one of the main public health problems in Indonesia because of its high morbidity and mortality. This research method is a "cross sectional study" where data collection is only carried out in only one period or only done once in one study (Budiarto, 2004). The population is all mothers who have children under five who live in Baru Village, PancurBatu, Deli Serdang District, which is 480 people. The sampling technique is by random sampling method. The sampling technique uses a random sampling method using a formula so that the sample is 96 people. The research instruments used in this study are using questionnaires which are divided into two parts, namely the first to find out the characteristics of respondents and the relationships between variables and the most influential variables in the incidence of diarrhea. Bivariate analysis data found that there was a relationship between breastfeeding, income, healthy latrines, hand washing with the incidence of diarrhea where the value of $p<0.005$. and there is no significant relationship between education, employment and clean water use with the incidence of diarrhea $p>0.05$. the community needs to understand about the incidence of diarrhea in infants and the factors that influence it so that they can make efforts to prevent the prevention of diarrhea independently by improving socio-economic behavior and clean and healthy living
\end{abstract}

Keywords: diarrhea, social, economy, hand washing

\section{PENDAHULUAN}

Menurut data UNICEF (The United Nations Children's Fund) dan WHO (World Health Organization) pada tahun 2009, diare merupakan penyebab kematian nomor dua pada balita di dunia, nomor tiga pada bayi dan nomor lima bagi sejumlah umur. Data UNICEF memperkirakan bahwa 1,5 juta anak meninggal dunia setiap tahunnya karena diare (Sindo, 2010). Di Indonesia anak-anak menderita diare lebih dari 12 kali per tahun dan hal ini yang menjadi penyebab kematian sebesar $15-34 \%$ dari semua penyebab kematian (Wardhani, 2012). Dari hasil Survey Kesehatan Rumah Tangga (SKRT) ini menunjukkan betapa penyakit diare tidak dapat dipandang sebelah mata, karena secara umum setiap tahunnya rata 100.000 anak meninggal dunia di Indonesia karena diare. Sebanyak 273 balita setiap harinya kehilangan nyawa (Mujianto, 2008).

Berdasarkan data yang diperoleh Dinas Kesehatan Provinsi Sumatera Utara, kasus kejadian diare di Kota Medan sepanjang tahun 2015 sebanyak 29.375 kasus, sedangkan tahun 2016, angka kesakitan diare sebanyak 29.769 kasus. Selain Medan, diare tahun 2015 terbanyak terjadi di Deli Serdang sebanyak 17.529 kasus, Langkat sebanyak 14.175 kasus, Serdang Bedagai sebanyak 11.962 (3 kasus kematian) dan Simalungun terjadi 32.428 kasus. Sedangkan tahun 2016, kota Medan masih menjadi peringkat pertama kasus diare sebanyak 29.769 kasus, diikuti Deli Serdang sebanyak 20.535 kasus, Langkat sebanyak 27.943 


\begin{tabular}{|c|c|c}
\hline JURNAL PENELITIAN KESMASY & VOL. 1 NO. 2 & $\begin{array}{c}\text { EDITION: NOVEMBER 2018 - } \\
\text { APRIL 2019 }\end{array}$ \\
\hline & http://ejournal.delihusada.ac.id/index.php/JPKSY \\
\cline { 2 - 3 } RECEIVED: 17 FEBRUARI 2019 & REVISED: 18 MARET 2019 & ACCEPTED: 28 APRIL 2019 \\
\hline
\end{tabular}

kasus (1 korban meninggal) dan Labuhan Batu Utara sebanyak 12.253 kasus, di Puskesmas Pancur Batu tahun 2016 terdapar 100 kasus (Tribun Medan, 2016).

Sebagian besar sumber air masyarakat di Desa Baru Kecamatan Pancur Batu kabupaten Deli Serdang adalah berasal dari sumur timbah, akan tetapi air yang terdapat di dalam sumur tersebut belum tentu bersih. Selain itu ibu tidak memberikan ASI eksklusif kepada balita sehingga membuat sistem imunitas balita sangat rentan. Tidak menggunakan jamban yang sehat sehingga lalat dengan mudah hinggap dan kemudian menyebarkan penyakit yang dapat menyebabkan diare.

Selain itu jika suatu rumah tangga berpenghasilan rendah, pada umumnya mempunyai sanitasi yang buruk dan kebersihan perorangannya juga buruk. Berkaitan dengan hal tersebut maka perlu dilakukan penelitian pada balita di Desa Baru Kecamatan Pancur Batu Kabupaten Deli Serdang. Karena masih banyak ibu-ibu yang belum mengetahui dengan pola hidup bersih dan sehat, hal ini berbahaya dilihat dari dari sistem pencernaan bayi/balita

\section{METODE}

Metode penelitian ini bersifat "cross sectional study" dimana pengumpulan data hanya dilakukan hanya dalam satu priode atau hanya dilakukan satu kali dalam satu penelitian (Budiarto, 2004).

Populasi seluruh ibu yang mempunyai balita yang tinggal di Desa Baru Kecamatan Pancur Batu Kabupaten Deli Serdang yaitu sebanyak 480 orang. Teknik pengambilan sampel dengan metode random sampling. Teknikpengambilansampelmenggunakanmeto de random sampling dengan menggunakan rumus sehingga di dapatkan sampel sebanyak 96 orang.

Instrumen penelitian yang digunakan dalam penelitian ini yaitu menggunakan kuesioner yang terbagi menjadi dua bagian yaitu yang pertama untuk mengetahui karakteristik responden dan hubungan antar variable serta variabel yang paling berpengaruh dalam kejadian diare

\section{HASIL DAN PEMBAHASAN}

Tabel 1. Karakteristik Responden

\begin{tabular}{|c|c|c|}
\hline Karakteristik & $\begin{array}{c}\text { Jumlah } \\
\text { (n) }\end{array}$ & $\begin{array}{c}\text { Persentase } \\
(\%)\end{array}$ \\
\hline \multicolumn{3}{|l|}{ Umur } \\
\hline$<30$ tahun & 35 & 36,5 \\
\hline$>30$ tahun & 61 & 63,5 \\
\hline Jumlah & 96 & 100,0 \\
\hline \multicolumn{3}{|l|}{ Pendidikan } \\
\hline SD & 12 & 12,5 \\
\hline SMP & 36 & 37,5 \\
\hline SMA & 28 & 29,2 \\
\hline Perguruan & 20 & 20,8 \\
\hline \multicolumn{3}{|l|}{ Tinggi (PT) } \\
\hline Jumlah & 96 & 100,0 \\
\hline \multicolumn{3}{|l|}{ Pekerjaan } \\
\hline Ibu Rumah & 62 & 64,6 \\
\hline \multicolumn{3}{|l|}{ Tangga (IRT) } \\
\hline Wiraswasta & 18 & 18,8 \\
\hline Pegawai & 16 & 16,6 \\
\hline \multicolumn{3}{|l|}{$\begin{array}{l}\text { Negeri Sipil } \\
\text { (PNS) }\end{array}$} \\
\hline Jumlah & 96 & 100,0 \\
\hline \multicolumn{3}{|l|}{ Umur Balita } \\
\hline$<3$ tahun & 22 & 22,9 \\
\hline 3 tahun & 34 & 35,4 \\
\hline$>3$ tahun & 40 & 41,7 \\
\hline Jumlah & 96 & 100,0 \\
\hline
\end{tabular}

Dari tabel di atas dapat dilihat bahwa berdasarkan umur responden sebanyak 61 dari 96 orang yaitu $(63,5 \%)$ berada pada umur > 30 tahun, berdasarkan pendidikan sebanyak 51 dari 96 orang yaitu $(53,1 \%)$ berpendidikan SMA, berdasarkan pekerjaan sebanyak 77 dari 96 orang yaitu $(80,2 \%)$ bekerja sebagai Ibu Rumah Tangga (IRT), dan berdasarkan umur balita sebanyak 40 dari 96 orang yaitu $(41,7 \%)$ berumur $>3$ tahun.

Tabel 2. Hasil Analisis Univariat

Jumlah Persentase 


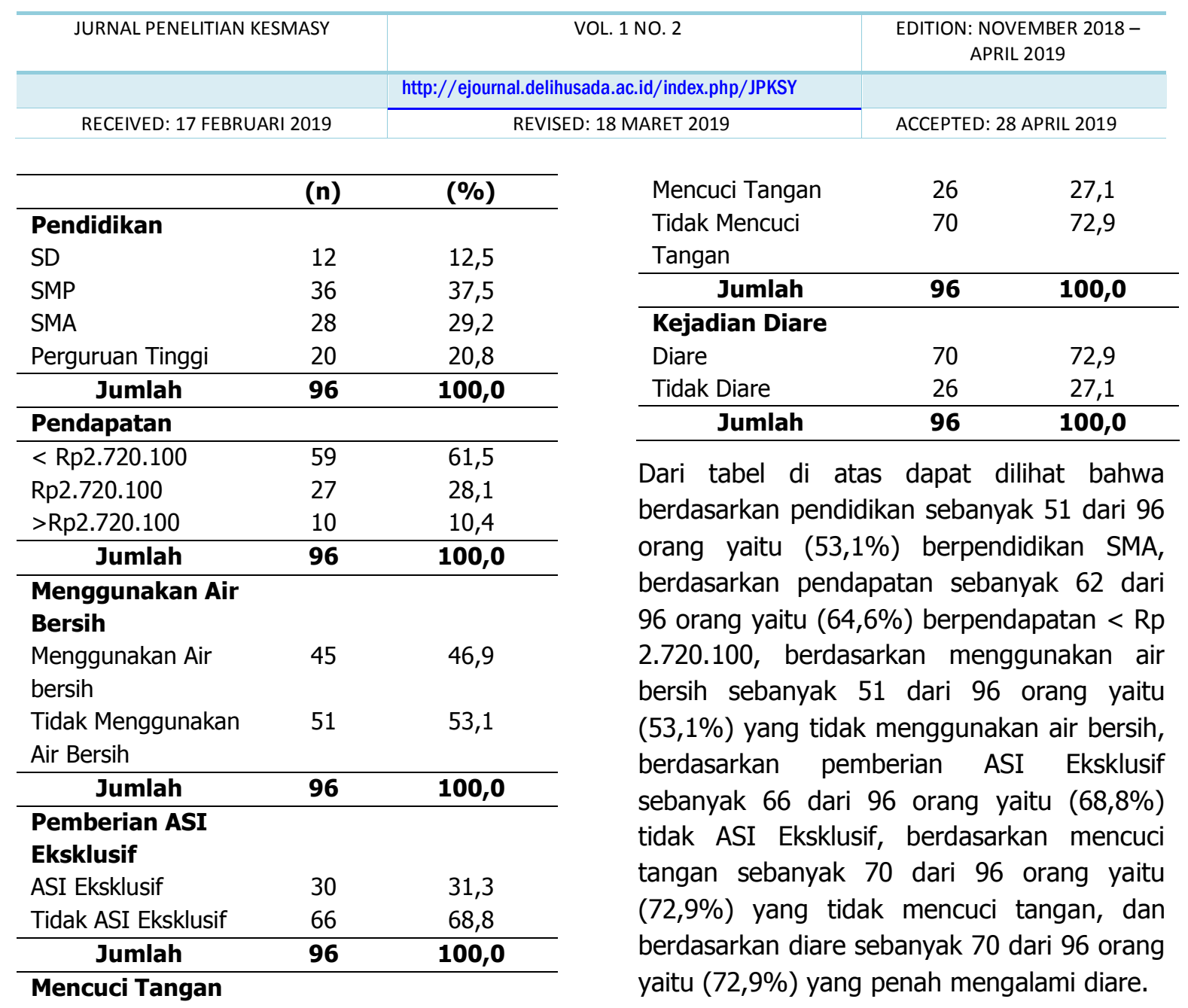

Tabel 3. Pendidikan Menurut Kejadian Diare Pada Balita

\begin{tabular}{|c|c|c|c|c|c|c|c|}
\hline \multirow{3}{*}{$\begin{array}{l}\text { Kejadian } \\
\text { Diare }\end{array}$} & \multicolumn{4}{|c|}{ Pendidikan } & \multirow{2}{*}{\multicolumn{2}{|c|}{ Jumlah }} & \multirow{3}{*}{$p$} \\
\hline & \multicolumn{2}{|c|}{$\begin{array}{c}\text { Pendidikan }<9 \\
\text { tahun }\end{array}$} & \multicolumn{2}{|c|}{$\begin{array}{c}\text { Pendidikan } \geq 9 \\
\text { tahun }\end{array}$} & & & \\
\hline & $\mathbf{N}$ & $\%$ & $\mathbf{N}$ & $\%$ & n & $\%$ & \\
\hline Diare & 36 & 51,4 & 34 & 48,6 & 70 & 100,0 & \\
\hline Tidak Diare & 12 & 46,2 & 14 & 53,8 & 26 & 100,0 & 0,646 \\
\hline
\end{tabular}

Tabel 4. Pendapatan Menurut Kejadian Diare Pada Balita

\begin{tabular}{|c|c|c|c|c|c|c|c|}
\hline \multirow{3}{*}{$\begin{array}{c}\text { Kejadian } \\
\text { Diare }\end{array}$} & \multicolumn{4}{|c|}{ Pendapatan } & \multirow{2}{*}{\multicolumn{2}{|c|}{ Jumlah }} & \multirow{3}{*}{$\boldsymbol{P}$} \\
\hline & \multicolumn{2}{|c|}{$<\operatorname{Rp} 2.720 .100$} & \multicolumn{2}{|c|}{$\geq \operatorname{Rp} 2.720 .100$} & & & \\
\hline & $\mathbf{N}$ & $\%$ & $\mathbf{N}$ & $\%$ & $\mathbf{n}$ & $\%$ & \\
\hline Diare & 48 & 68,6 & 22 & 31,4 & 70 & 100 & \\
\hline Tidak Diare & 11 & 42,3 & 15 & 57,7 & 26 & 100 & 0,019 \\
\hline
\end{tabular}

Tabel 5 Pemberian ASI Eksklusif Menurut Kejadian Diare Pada Balita

\begin{tabular}{|c|c|c|c|c|c|c|c|}
\hline \multirow{3}{*}{$\begin{array}{l}\text { Kejadian } \\
\text { Diare }\end{array}$} & \multicolumn{4}{|c|}{ Pemberian ASI Eksklusif } & \multirow{2}{*}{\multicolumn{2}{|c|}{ Jumlah }} & \multirow{3}{*}{$\boldsymbol{p}$} \\
\hline & \multicolumn{2}{|c|}{ Tidak } & \multicolumn{2}{|c|}{ Ya } & & & \\
\hline & $\mathbf{N}$ & $\%$ & $\mathbf{N}$ & $\%$ & $\mathbf{n}$ & $\%$ & \\
\hline Diare & 54 & 77,1 & 16 & 22,9 & 70 & 100,0 & 0,004 \\
\hline Tidak Diare & 12 & 46,2 & 14 & 53,8 & 26 & 100,0 & \\
\hline
\end{tabular}

Tabel 6. Distribusi Mencuci Tangan Menurut Kejadian Diare Pada Balita 


\begin{tabular}{|c|c|c|c|c|c|c|c|}
\hline \multicolumn{3}{|c|}{ JURNAL PENELITIAN KESMASY } & \multicolumn{4}{|c|}{ VOL. 1 NO. 2} & $\begin{array}{l}\text { EDITION: NOVEMBER } 2018- \\
\text { APRIL } 2019\end{array}$ \\
\hline & & \multicolumn{5}{|c|}{ http://ejournal.delihusada.ac.id/index.php/JPKSY } & \\
\hline \multicolumn{3}{|c|}{ RECEIVED: 17 FEBRUARI 2019} & \multicolumn{4}{|c|}{ REVISED: 18 MARET 2019} & ACCEPTED: 28 APRIL 2019 \\
\hline \multirow{3}{*}{$\begin{array}{l}\text { Kejadian } \\
\text { Diare }\end{array}$} & \multicolumn{4}{|c|}{ Mencuci Tangan } & \multirow{2}{*}{\multicolumn{2}{|c|}{ Jumlah }} & \multirow{3}{*}{ 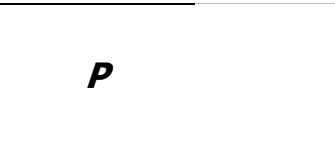 } \\
\hline & \multicolumn{2}{|c|}{ Tidak } & \multicolumn{2}{|c|}{ Ya } & & & \\
\hline & $\mathbf{N}$ & \multirow{2}{*}{78,6} & $\mathbf{n}$ & $\%$ & $\mathbf{N}$ & $\%$ & \\
\hline Diare & 55 & & 15 & 21,4 & 70 & 100,0 & \multirow[t]{2}{*}{0,041} \\
\hline Tidak Diare & 15 & 57,7 & 11 & 42,3 & 26 & 100,0 & \\
\hline
\end{tabular}

Tabel 7. Hasil Akhir Regresi Logistik Hubungan Sosial Ekonomi Dan Perilaku Hidup Bersih Dan Sehat Dengan Kejadian Diare Pada Balita

\begin{tabular}{lccccc}
\hline \multicolumn{1}{c}{ Variabel } & B & Sig & Exp B & \multicolumn{2}{c}{ 95\% CI } \\
\cline { 5 - 6 } & & & & Lower & Upper \\
\hline Pendapatan & 0,764 & 0,138 & 2,148 & 0,782 & 5,897 \\
\hline ASI Eksklusif & 1,045 & 0,042 & 2,844 & 1,036 & 7,806 \\
Mencuci Tangan & 0,505 & 0,358 & 1,658 & 0,564 & 4,869 \\
Jamban Sehat & 0,650 & 0,208 & 1,915 & 0,696 & 5,270 \\
$\quad$ Constant & -2.122 & 0,000 & 0,120 & & \\
\hline
\end{tabular}

Dari tabel 3 di atas dapat dilihat kejadian diare pada ibu yang berpendidikan diketahui $\mathrm{p}=0,646$ pada taraf nyata $\mathrm{a}=0,05$ dari analisis juga didapat nilai $\mathrm{RP}=1,235$ dan bermakna secara statistik ( $95 \% \mathrm{CI}=0,501-$ $3,045)$ ini berarti ada hubungan yang tidak bermakna.

Dari tabel 4 di atas dapat dilihat kejadian diare pada ibu yang berpendapatan $<\mathrm{Rp}$ 2.720.100 lebih besar beresiko mengalami diare sebanyak 48 dari 96 orang $(68,6 \%)$ diketahui $\mathrm{p}=0,019$ pada taraf nyata $\mathrm{a}=$ 0,05 dari analisis juga didapat nilai $\mathrm{RP}=$ 2,975 dan bermakna secara statistik (95\% CI sebesar $1,177-7,521$ ) ini menyatakan ada hubungan yang bermakna yang berarti bahwa ibu yang berpendapatan $<\mathrm{Rp}$ 2.720.100 2,975 kali lebih besar beresiko mengalami diare pada balita dibandingkan dengan ibu yang berpendapatan $\geq \mathrm{Rp}$ 2.720.100.

Dari tabel 5 di atas dapat dilihat kejadian diare pada ibu yang pemberian ASI tidak Eksklusif lebih besar beresiko mengalami diare pada balita sebanyak 54 dari 96 orang $(77,1 \%)$ diketahui $\mathrm{p}=0,004$ pada taraf nyata $\mathrm{a}=0,05$ dari analisis juga didapat nilai $\mathrm{RP}=3,938$ dan bermakna secara statistik $(95 \%$ CI $=1,520-10,199)$ ini menyatakan ada hubungan yang bermakna, yang berarti ibu yang pemberian ASI tidak eksklusif 3,938 kali lebih besar beresiko mengalami diare pada balita dibandingkan dengan ibu yang pemberian ASI eksklusif.

Dari tabel 6 di atas dapat dilihat kejadian diare pada ibu yang tidak mencuci tangan lebih beresiko mengalami diare pada balita sebanyak 55 dari 96 orang (78,6\%) diketahui $p=0,041$ pada taraf nyata $a=$ 0,05 dari analisis juga didapat nilai $\mathrm{RP}=$ 2,689 dan bermakna secara statistik (95\% $\mathrm{CI}=1,024-7,058)$ ini menyatakan ada hubungan yang bermakna, yang berarti ibu yang tidak mencuci tangan 2,689 kali lebih beresiko mengalami diare pada balita dibandingkan dengan ibu yang mencuci tangan.

Hasil analisis multivariat (tabel 7) dengan regresi logistik, nilai prevalence ratio untuk variabel pemberian ASI eksklusif sebesar 2,844 artinya ibu yang pemberian ASI tidak eksklusif 2,844 kali lebih besar kemungkinan mengalami diare pada balita dibandingkan ibu yang pemberian ASI eksklusif, nilai prevalence ratio untuk variabel pendapatan sebesar 2,148 artinya ibu yang berpendapatan < Rp 2.720.100 2,148 kali lebih besar kemungkinan mengalami diare pada balita dibandingkanibu yang berpendapatan $\geq \mathrm{Rp} 2.720 .100$, nilai prevalence ratio. nilai prevalence ratio untuk variabel mencuci tangan sebesar 1,658 


\begin{tabular}{c|c|c}
\hline JURNAL PENELITIAN KESMASY & VOL. 1 NO. 2 & $\begin{array}{c}\text { EDITION: NOVEMBER 2018 - } \\
\text { APRIL 2019 }\end{array}$ \\
\hline & http://ejournal.delihusada.ac.id/index.php/JPKSY & \\
\cline { 2 - 3 } RECEIVED: 17 FEBRUARI 2019 & REVISED: 18 MARET 2019 & ACCEPTED: 28 APRIL 2019 \\
\hline
\end{tabular}

artinya ibu yang tidak mencuci tangan 1,658 kali lebih besar kemungkinan mengalami diare pada balita dibandingkan yang mencucitangan.

Penelitian ini sejalan dengan Hasil penelitian Sandu (2014), Hasil penelitian Edwin (2013) dan Stefen (2013) yang menunjukkan bahwa sebagian besar responden pernah mengalami diare menunjukkan ada berbagai permasalahan baik dipandang dari sudut pandang kesehatan lingkungan maupun perilaku kesehatan. Pada daerah peneitian sangat jarang dijumpai wastafel yang diperuntukan anggota keluarga mencuci tangan dengan sabun dengan menggunakan sabun, kebanyakan responden mencuci tangan dengan cara dicelupkan air dalam bak penampungan untuk cuci tangan, kondisi ini memungkinkan terjadinya penularan diantara anggota keluarga karena menggunakan tempat cuci dan air yang sama. Kebiasaan di daerah penelitian mencuci tangan kebanyakan hanya dilakukan jika secara fisik tangan terlihat kotor, misalnya terkena tanah, baru responden mencuci tangan.

\section{KESIMPULAN}

1. Ada hubungan yang yang bermakna antara pemberian ASI Eksklusif dengan kejadian diare pada balita dimana ibu yang pemberian ASI tidak eksklusif 2,844 kali lebih besar kemungkinan mengalami diare pada balita dibandingkan ibu yang pemberian ASI eksklusif, diketahui nilai $p=0,004$ dengan nilai $p<0,05$ dan $a>1$.

2. Ada hubungan yang bermakna antara pendapatan dengan kejadian diare pada balita dimana ibu yang berpendapatan < Rp 2.720.100 2,148 kali lebih besar kemungkinan mengalami diare dibandingkan dengan yang berpendapatan $\geq \operatorname{Rp~2.720.100,~}$ diketahui nilai $p=0,019$ dengan nilai $p$ $<0,05$ dan $a>1$.

3. Ada hubungan yang bermakna antara jamban sehat dengan kejadian diare pada balita dimana ibu yang tidak memiliki jamban sehat 1,915 kali lebih besar kemungkinan mengalami diare dibandingkan dengan yang memiliki jamban sehat, diketahui nilai $p=0,035$ dengan nilai $p<0,05$ dan $a>1$.

4. Ada hubungan yang bermakna antara mencuci tangan dengan kejadian diare pada balita dimana ibu yang tidak mencuci tangan 1,658 kali lebih besar kemungkinan mengalami diare dibandingkan dengan yang mencuci tangan, diketahui nilai $\mathrm{p}=0,041$ dengan nilai $p<0,05$ dan $a>1$.

Ada hubungan yang tidak bermakna antara pendidikan, pekerjaan, dan penggunaaan air bersih dengan kejadian diare pada balita dengan nilai $\mathrm{p}>0,05$ dan $\mathrm{a}<1$

\section{SARAN}

1. Diharapkan Kepala Desa di Desa Baru Kecamatan Pancur Batu Kabupaten Deli Serdang untuk dapat membuat kebijakan dalam rangkan memberikan informasi penyebab, bahaya dan penanggulangan diare pada balita.

2. Upaya meningkatkan pengetahuan tentang sosial ekonomi dan perilaku hidup bersih dan sehat dengan kejadian diare pada balita dengan salah satu upaya promosi kesehatan dengan metode penyuluhan yaitu ceramah leaflet.

3. Bagi masyarakat perlu memahami tentang kejadian diare pada balita dan faktor penyebab yang mempengaruhi agar dapat melakukan upaya pencegahan penanggulangan diare secara mandiri dengan cara memperbaiki sosial ekonomi dah perilaku hidup bersih dan sehat.

4. Perlu penelitian lebih lanjut untuk mengetahui variabel lain yang di duga berpengaruh terhadap kejadian diare pada balita. 


\begin{tabular}{|c|c|c|}
\hline JURNAL PENELITIAN KESMASY & VOL. 1 NO. 2 & $\begin{array}{c}\text { EDITION: NOVEMBER } 2018- \\
\text { APRIL } 2019\end{array}$ \\
\hline & http://ejournal.delihusada.ac.id/index.php/JPKSY & \\
\hline
\end{tabular}

\section{DAFTAR PUSTAKA}

Adik., 2014. Kesehatan Masyarakat Di Indonesia Konsep Aplikasi Dan Tantangan, Jakarta : Rajawali Pers.

Adisasmito, Wiku., 2007. Sistem Kesehatan, Jakarta : Raja Grafindo Persada.

Ahmadi, Abu., 2003. Ilmu Sosial Dasar, Jakarta : PT. Rineka Cipta.

Alhidayad., 2007. Analisis Pendapatan Petani Di Desa Pulau Pandan Kecamatan Limun Kabupaten Sarolangan, Skripsi, Program Ekstensi Fakultas Ekonomi UNEJ Jember.

Amaliya Lydia., 2010. Hubungan Faktor Lingkungan Dan Sosial Ekonomi Dengan Kejadian Diare Pada Balita Di Kelurahan Pisangan Ciputat Timur, Laporan Penelitian, Program Studi Pendidikan Dokter Fakultas Kedokteran Dan Ilmu Kesehatan Universitas Islam Negeri Syarif Hidayatullah Jakarta

Anik., 2017. Ilmu Kesehatan Anak Dalam Kebidanan, Jakarta : Trans Info Media.

2013. Perilaku Hidup Bersih Dan Sehat (PHBS), Jakarta : Trans Info Media

Arikunto, Suharsini., 006. Prosedur Penelitian Suatu Pendekatan Praktik, Edisi revisi 2006, Jakarta : Rineka Cipta.

Atikah., 2012. Perilaku Hidup Bersih Dan Sehat (PHBS), Yogyakarta : Medical Book.

Ernawati., 2006. Hubungan Faktor Sosial Ekonomi, Higiene Sanitasi Lingkungan, Tingkat Konsumsi Dan Infeksi Dengan Status Gizi Anak Usia 2-5 Tahun Di Kabupaten Semarang Tahun 2003, Tesis Magister Gizi Masyarakat, Program Pascasarjana Universitas Diponegoro Semarang.

Mujahidin., Medan Mendominasi Diare Tertinggi Di Sumut, Kamis, 28 Naret 2016 22:14, medan.tribunnews.com.

Nadjib, M.Bustan., 2012. Pengantar Epidemiologi, Jakarta : Rineka Cipta
Ngastiah., 2005. Perawatan Anak Sakit, Editor Monica Ester, Jakarta : EGC

Notoatmodjo, Soekidjo., 2003. Pendidikan Dan Perilaku Kesehatan, Jakarta : PT. Rineka Cipta.

Sandu., 2014. Kejadian Diare Berdasarkan Perilaku Hidup Bersih Dan Sehat (PHBS) Dan Sanitasi Lingkungan Rumah Dengan Di Wilayah Puskesmas Tamis Di Nusa Tenggara Timur, Jurnal Kesehatan Masyarakat, Stikes Surya Mitra Husada Kediri.

Sandu., 2014. Kejadian Diare Berdasarkan Perilaku Hidup Bersih Dan Sehat (PHBS) Dan Sanitasi Lingkungan Rumah Dengan Di Wilayah Puskesmas Tamis Di Nusa Tenggara Timur, Jurnal Kesehatan Masyarakat, Stikes Surya Mitra Husada Kediri.

Stefen., 2013. Hubungan Sanitasi Dasar Rumah Dan Perilaku Ibu Rumah Tangga Dengan Kejadian Diare Pada Balita Di Desa Bena Nusa Tenggara Timur, Jurnal Kesehatan Masyarakat, Departemen Kesehatan Lingkungan Fakultas Kesehatan Masyarakat Universitas Airlangga.

Sugiyono., 2007. Statistik untuk Penelitian, Bandung : Alfabeta.

Supariasa I.D.N., et.al, 2002. Penilaian Status Gizi, Jakarta : EGC

Widyastuti., 2005. Epidemiologi Suatu Pengantar, Edisi 2, Jakarta : EGC.

Zulkifli., 2011. Faktor Risiko Diare Shigellosis Pada Anak Balita, Artikel Penelitian, Bagian Epidemiologi Fakultas Kesehatan Masyarakat Universitas Hasanuddin Makassar. 